\title{
Separation of Iodide, Bromide, and Chloride From One Another and Their Subsequent Determination
}

\author{
Thomas J. Murphy, W. Stanley Clabaugh, and Raleigh Gilchrist \\ A method is described for separating iodide, bromide, and chloride from one another. \\ First, the iodide ion is oxidized to elementary iodine by hydrogen peroxide in weakly acid \\ solution and the iodine removed by distillation. Next, bromide is oxidized to bromine without \\ affecting the chloride ion by use of a controlled concentration of nitric acid as oxidizing agent. \\ After removal of bromine by distillation, chloride remains in the residual solution. \\ Determination of the individual halides depends on the quantity of each. If in trace \\ amounts, a turbidimetric method is used; if in larger amounts, potentiometric titration with \\ silver nitrate is used. \\ A description of the apparatus used is also given.
}

\section{Introduction}

Many of the methods described in the literature for the separation of iodide, bromide, and chloride from one another and for their subsequent determination yield unsatisfactory results. In the separation of iodide only from a mixture of the three halides, the published methods do report accurate results. Iodide is usually separated by oxidizing it with nitrous acid or ferric sulfate in a dilute solution of sulfuric acid [1] ${ }^{1}$ and volatilizing the liberated iodine. The separation of bromide from chloride is a more difficult matter. In 1928 Wales [2] studied the methods reported in the literature and found the method of Winkler [3] to be the most promising. Winkler treated a mixture of bromide and chloride with sulfuric acid and permanganate and distilled out the bromine. In 1931 Freeman [4] reported this method to be unsatisfactory and recommended a modification, but in 1942 he [5] reported unsatisfactory results with his own revision. He stated that in this method, as well as in the others studied, the principal cause of error was the formation of free chlorine, which caused high results, or the formation of bromate, which caused low results. In the best method that he studied for the separation and determination of iodide, bromide, and chloride, the recovery of bromide was only 95 percent.

Because of this lack of a reliable method, a study was undertaken and a method developed by which the three halogens can be quantitatively separated from one another. The method yields accurate results regardless of the relative concentrations of the three halides.

\section{Discussion}

\subsection{Separation of Iodide from Bromide and Chloride}

In weakly acid solution it is possible to oxidize iodide to iodine with hydrogen peroxide without oxidizing either bromide or chloride. In solutions containing iodide, bromide, and chloride and hydrogen peroxide, the following are the significant reactions which can occur. The free-energy values,

\footnotetext{
1 Figures in brackets indicate the literature references at the end of this paper.
}

in kilocalories per mole, are calculated from values reported by Latimer [6], as follows:

$\begin{array}{ll}\text { (1) } \mathrm{H}_{2} \mathrm{O}_{2}+\mathrm{H}^{+}+2 \mathrm{I}^{-} & =\mathrm{I}_{2}+2 \mathrm{H}_{2} \mathrm{O} ; \\ \text { (2) } \mathrm{H}_{2} \mathrm{O}_{2}+\mathrm{I}_{2} & =\mathrm{O}_{2}+2 \mathrm{H}^{+}+2 \mathrm{I}^{-} ; \\ \text {(3) } \mathrm{H}_{2} \mathrm{O}_{2}+2 \mathrm{H}^{+}+2 \mathrm{Br}^{-} & =\mathrm{Br}_{2}+2 \mathrm{H}_{2} \mathrm{O} ; \\ \text { (4) } \mathrm{H}_{2} \mathrm{O}_{2}+\mathrm{Br}_{2} & =\mathrm{O}_{2}+2 \mathrm{H}^{+}+2 \mathrm{Br}^{-} ; \\ \text {(5) } \mathrm{H}_{2} \mathrm{O}_{2}+2 \mathrm{H}^{+}+2 \mathrm{Cl}^{-} & =\mathrm{Cl}_{2}+2 \mathrm{H}_{2} \mathrm{O} ; \\ \text { (6) } \mathrm{H}_{2} \mathrm{O}_{2}+\mathrm{Cl}_{2} & =\mathrm{O}_{2}+2 \mathrm{H}^{+}+2 \mathrm{Cl}^{-} ; \\ \text {(7) } \mathrm{H}_{2} \mathrm{O}_{2} & =\mathrm{H}_{2} \mathrm{O}+\frac{1}{2} \mathrm{O}_{2} ;\end{array}$

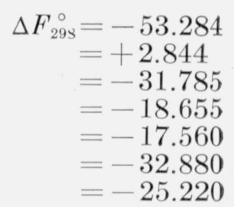

The large negative values of $\Delta F$ show that all of the reactions except reaction (2) tend to take place. At a $\mathrm{pH}$ of 5, reactions (1) and (2) proceed at about the same rate [7], the net results of the reaction being the decomposition of hydrogen peroxide. As the acidity is increased, reaction (1) takes place at a faster rate and reaction (2) at a slower rate until at a $\mathrm{pH}$ of 1 the rate of reduction of iodine is negligible. If the iodine formed is removed from the solution, reaction (1) can go to completion. However, as the acidity is increased it is possible to oxidize a small amount of bromide to bromine (reaction 3). Reaction (4) is much faster than reaction (3) [8], but as the acidity is increased reaction (3) is favored. As the rate of reaction between bromine and peroxide is rapid in neutral or weakly acid solution and the rate of oxidation of bromide slow, it follows that any bromine formed by reaction (3) would be reduced rapidly, with the resultant decomposition of hydrogen peroxide (reaction 7). However, if some of the bromine produced by reaction (3) were removed either as bromine or iodine monobromide (through reaction with the liberated iodine in reaction (1) before conversion to bromide by reaction (4), it would be possible to lose some of the bromine. This actually proves to be the case. For example, when $3 \mathrm{~g}$ of sodium bromide in $100 \mathrm{ml}$ of water was treated with $3 \mathrm{ml}$ of hydrogen peroxide and $2 \mathrm{ml}$ of phosphoric acid, and the solution boiled, bromine vapor could be seen distilling over. However, when the bromide content was decreased to $1 \mathrm{~g}$ of sodium bromide in $200 \mathrm{ml}$ of water and the acidity adjusted to a $\mathrm{pH}$ of 1 with phosphoric acid, no bromine could be seen distilling over, and a test of the distillate showed it to contain only $0.2 \mathrm{mg}$ of bromide. This error would be negligible for large amounts of iodide in the presence of small amounts of bromide. How- 
ever, to determine small amounts of iodide in the presence of a large amount of bromide, the distillate obtained must be again treated with hydrogen peroxide and phosphoric acid and redistilled. When this is done no bromine is detected in the distillate. When large amounts of both iodide and bromide occur together, bromine may be lost as iodine monobromide, if the acidity is not controlled carefully. When enough phosphoric acid is added at the start so that the resultant $\mathrm{pH}$ will be 1 after the iodine is removed, considerable bromide is lost as iodine monobromide. But when peroxide is added first, the solution heated to boiling, and the acid added slowly as the iodine distills out, only a negligible amount of bromide is lost.

Reactions (5) and (6) both take place at about the same rate, with the resultant decomposition of hydrogen peroxide [9]. At low acidity, only a negligible amount of chlorine distills, even from fairly concentrated chloride solutions. Thus under proper conditions it is possible to separate quantitatively iodide from bromide and chloride.

\subsection{Separation of Bromide from Chloride}

It has been found that nitric acid in suitable concentration will quantitatively oxidize bromide to bromine without oxidizing chloride to chlorine. Kebler [10] and Chamot and Mason [11] both used this reaction for the qualitative separation of bromide from chloride, but apparently no attempt was made to find out if the reaction could be made quantitative under proper conditions. Experiments showed that in diluted nitric acid $(1+9)^{2}$ the oxidation was complete but slow and that in diluted nitric acid $(1+2)$ chlorine begins to distill. It was observed experimentally that satisfactory results were obtained when the range of nitric acid concentration was from $(1+6)$ to $(1+3)$. The nitric acid concentration used in the experimental work was $(1+5)$. However, it was found that under these conditions a small amount of chloride is lost as chlorine. For example, when 20 $\mathrm{ml}$ of nitric acid was added to $100 \mathrm{ml}$ of water containing $1 \mathrm{~g}$ of potassium chloride and $25 \mathrm{ml}$ of the solution distilled into hydrazine sulfate solution, the distillate was found to contain $0.5 \mathrm{mg}$ of chloride. In more dilute solutions of chloride and of acid the error is even less. This error would be negligible for large amounts of bromide in the presence of small amounts of chloride, but a second treatment and distillation is necessary in the case of large amounts of chloride in the presence of small amounts of bromide. This indicates that it is possible to separate quantitatively bromide from chloride.

\section{Reagents Used}

Potassium Iodide. The potassium iodide used was prepared by Mark Swanson, formerly of the Bureau. The method of preparation is not known. It was

2 Throughout this paper, whenever the use of an acid is prescribed with no indication of strength or dilution, the acid to be used is the concentrated acid. Dilutions are indicated by the volumes cf acid and water mixed to prepare a dilute Dilutions are indicated by the volumes cf acid and water mixed to prepare a dilute
reagent. Diluted nitric $(1+x)$ means a diluted acid prepared by mixing 1 volume of the concentrated acid with $x$ volumes of distilled water. found to contain 0.0003 percent of bromide and 0.0003 percent of chloride.

Sodium Bromide. A survey of available bromide salts showed that they all contained chloride. The sodium bromide used in these experiments was prepared from sodium carbonate and hydrobromic acid as follows:

An approximately 30-percent solution of sodium carbonate, prepared from sodium carbonate containing 0.002 percent of chloride, was filtered through a glass filter of fine porosity. Sodium bicarbonate was precipitated from this solution by saturation with carbon dioxide. The mixture was cooled in an ice bath, and the salt was caught on a porous glass filter, washed with cold water, and sucked dry. The sodium bicarbonate so obtained was redissolved and the solution acidified with specially prepared hydrobromic acid, containing 0.0004 percent of chloride, to the end point of methyl red. The solution was boiled to expel carbon dioxide, evaporated to a small volume on the steam bath, cooled, filtered, and the resulting salt washed with 95-percent ethyl alcohol. This product was found to contain 0.0002 percent of iodide and 0.006 percent of chloride.

Potassium Chloride. The potassium chloride used was of ACS reagent quality and was found to contain 0.0006 percent of iodide and 0.0002 percent of bromide.

Phosphoric Acid. The phosphoric acid used was of ACS reagent quality and was found to contain less than 0.0005 percent of combined halides as chloride.

Hydrogen Peroxide. The hydrogen peroxide used was 30-percent peroxide of ACS reagent quality. It was found to contain less than 0.0005 percent of combined halides as chloride.

Nitric Acid. The nitric acid used was of ACS reagent quality. It was found to contain less than 0.00001 percent of combined halides as chloride.

Hydrazine Sulfate. The hydrazine sulfate was supplied commercially. It was found to contain less than 0.0005 percent of combined halides as chloride.

Silver Nitrate. The silver nitrate used was of ACS reagent quality. It was found to contain less than 0.00005 percent of combined halides as chloride.

Potassium Permanganate Reagent Solution. A survey of commercial samples showed them all to be high in chloride content. The following method of purification was used:

Seventy-five grams of potassium permanganate was dissolved in $1,250 \mathrm{ml}$ of water, and $10 \mathrm{ml}$ of nitric acid was added. The solution was heated to about $45^{\circ} \mathrm{C}$, and a stream of halide-free air was passed through the solution. At intervals the evolved gases were passed through a 2-percent solution of hydrazine sulfate for $1 / 2$ hour, and this solution was tested for chloride with silver nitrate. The treatment was continued until chlorine was no longer detected. This solution, which contained about $0.9 \mathrm{~g}$ of potassium permanganate in $15 \mathrm{ml}$, was found to contain less than 0.0001 percent of chloride. 


\section{Preparation and Standardization of Solutions}

\subsection{Silver Nitrate on a Weight Basis (Approxi- mately 0.1 Molal)}

About $70 \mathrm{~g}$ of silver nitrate was dissolved in 4 liters of water. Two $50-\mathrm{ml}$ portions and a $60-\mathrm{ml}$ portion were measured by means of a weight buret. The portions were concentrated on a steam bath to a volume of about $10 \mathrm{ml}$, and $10 \mathrm{ml}$ of $1 N$ hydrochloric acid was added to each. The solutions were diluted to $150 \mathrm{ml}$ and stored in the dark overnight. The precipitates were collected in filtering crucibles of fine porosity, washed with very dilute hydrochloric acid $(1+999)$, dried at $120^{\circ} \mathrm{C}$, and weighed. The concentration was found to be $0.010625 \mathrm{~g}$ of silver per gram of solution.

\subsection{Silver Nitrate on a Volumetric Basis (Approximately 0.01 Normal)}

The same procedure as above was followed except that the $50-\mathrm{ml}$ and $60-\mathrm{ml}$ portions were accurately measured volumetrically instead of being weighed. The solution was found to be $0.10256 N$ and was diluted tenfold before use.

\subsection{Iodide}

Twenty grams of the potassium iodide was dissolved in 2 liters of distilled water. Weighed portions of the solution of about $45 \mathrm{~g}$ to $60 \mathrm{~g}$ were diluted to $100 \mathrm{ml}$, and $0.1 \mathrm{molal}$ silver nitrate was added by means of a weight buret to within about 1 percent of the equivalence point. The titration was completed with $0.01 \mathrm{~N}$ silver nitrate potentiometrically. The concentration was found to be $0.0077132 \mathrm{~g}$ of iodide per gram of solution.

\subsection{Bromide}

Twenty grams of the sodium bromide was dissolved in 2 liters of distilled water. The same procedure was used as for the standardization of the iodide solution. The concentration was found to be $0.0078208 \mathrm{~g}$ of bromide per gram of solution.

\subsection{Chloride}

Twenty grams of the potassium chloride was dissolved in 2 liters of distilled water. The same procedure was used as for the standardizations of the iodide and bromide solutions, except that the solution was cooled in an ice bath during the titration. The concentration was found to be 0.0047904 $\mathrm{g}$ of chloride per gram of solution.

\section{Procedure Used for Separating Iodide, Bromide, and Chloride}

\subsection{Halides Present as Major Constituents}

The distilling apparatus was assembled as in figure 1. Twenty-five milliliters of a 2-percent solution of hydrazine sulfate was placed in flask G and $25 \mathrm{ml}$ of a 0.5-percent solution of hydrazine sulfate was placed in flask I. About 4 in. of mercury was placed in gas washing bottle $\mathrm{K}$ and $50 \mathrm{ml}$ of
$1 N$ silver nitrate was placed in gas washing bottle L. When this system was connected to a vacuum line, the silver nitrate solution served to wash any halide from the air, and the mercury maintained the pressure on the system about 4 in. below atmospheric pressure. In this manner no halogen was lost through the glass joints, as air would have been drawn in through a loosely fitting joint.

By means of weight burets and the standardized halide solutions, synthetic mixtures of halide salts were obtained containing varving amounts of each halide. The amounts added were such that a total of about $1 \mathrm{~g}$ of combined halide salts was present.

The standardized solutions were added directly from weight burets to flask $A$ to avoid error due to transfer. This apparatus and method of adding the known amounts of halide solutions were used throughout all the separations, unless otherwise noted.

Separation of Iodide. The synthetic halide mixture in flask $\mathrm{A}$ was diluted to about $200 \mathrm{ml}$. The system was closed and connected to a vacuum line. The vacuum was regulated so that air slowly bubbled through the mercury. One milliliter of 30-percent hydrogen peroxide was added through delivery funnel $\mathrm{B}$, and the solution was haated to boiling. Diluted phosphoric acid $(1+99)$ was placed in the delivery funnel and showly dropped into the solution until iodine began to be evolved. The addition of

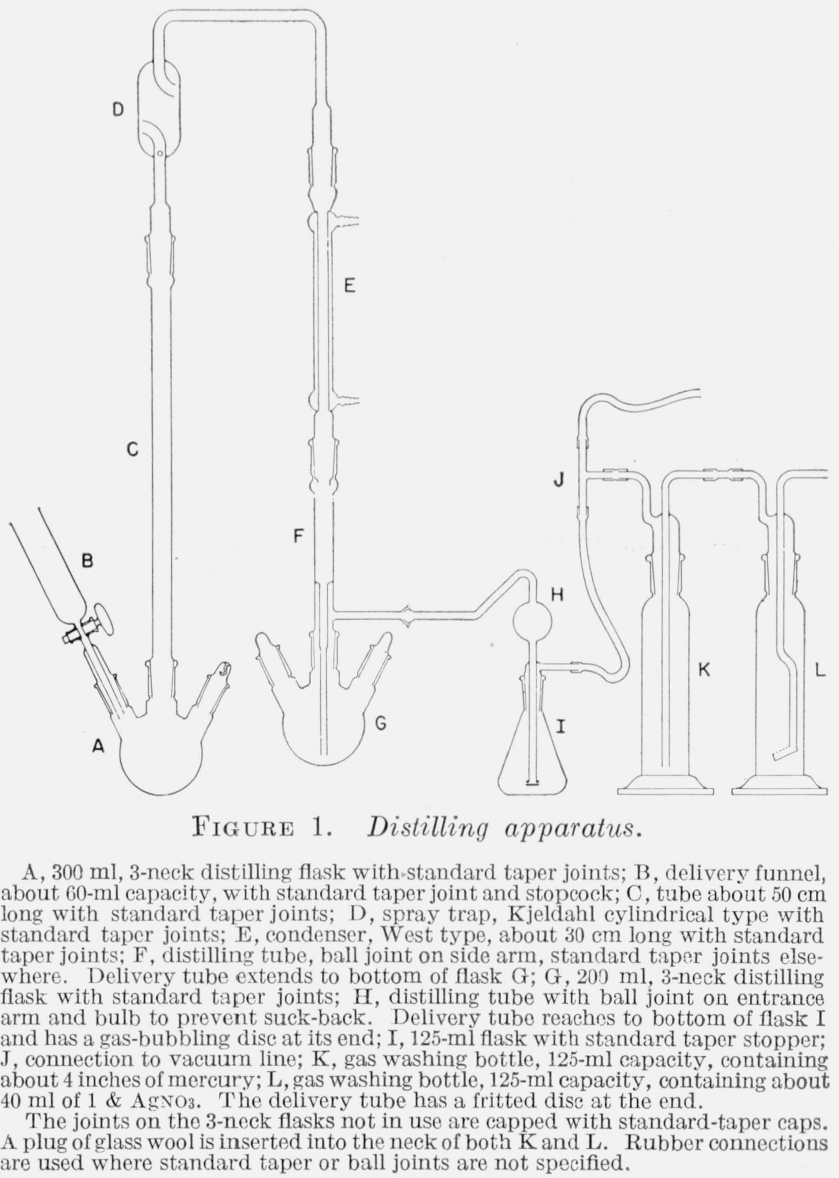


phosphoric acid was stopped and the liberated iodine removed by distillation. More diluted phosphoric acid was added and the iodine liberated again removed. This addition of phosphoric acid and removal of iodine was continued until iodine was no longer liberated from the solution. The amount of diluted phosphoric acid necessary will depend on the quantity of iodide present. Usually, 10 to $25 \mathrm{ml}$ of the diluted acid is required. The distillation was continued until all of the iodine was distilled into flask G. ${ }^{3}$ It was necessary to keep the hydrazine sulfate solution in flask $\mathrm{G}$ warm because iodine does not react readily with the cool solution. The rate at which the iodine distilled was kept slow, so that only about $25 \mathrm{ml}$ to $30 \mathrm{ml}$ of solution distilled. About $1 \mathrm{ml}$ of diluted phosphoric acid $(1+99)$ and $0.2 \mathrm{ml}$ of 30 -percent hydrogen peroxide were added through the delivery funnel and the color of the solution noted. If a color developed, the iodine formed was removed by distillation and the treatment repeated until no color was developed. ${ }^{4}$ The solution in flash I was poured into flask G. Tubes $\mathrm{F}$ and $\mathrm{H}$ and flask $\mathrm{I}$ were rinsed and the washings caught directly in flask $\mathrm{G}$. The flask and contents were reserved for the determination of iodide.

Separation of Bromide. The apparatus was reassembled as above, with another 3-neck flask for G. Sixty milliliters of diluted nitric acid $(1+1)$ was added through delivery funnel $B$, and the solution was refluxed until all the hydrogen peroxide was decomposed. (With a little practice, this can be determined by noting a change in the bubble formation.) The bromine produced was slowly distilled, and the distillation continued for 15 minutes after the residual solution was colorless and no trace of bromine could be seen anywhere in the system. The rate of distillation was kept slow, and the volume in flask A was never allowed to drop below $120 \mathrm{ml}$. The solution in flask I was poured into flask G. Tubes F and $\mathrm{H}$ and flask I were rinsed and the washings caught directly in flask G. The flask and contents were reserved for the determination of the bromide.

Separation of Chloride. As the iodide and bromide originally present had already been removed, the only halide remaining in flask $\mathrm{A}$ was the chloride. The flask and contents were reserved for the determination of chloride.

\subsection{Iodide as the Major Constituent, Bromide and Chloride as Minor Constituents}

Separation of Iodide. The method of separation used was the same as for the separation of iodide under 5.1, except that the concentration and method of addition of the phosphoric acid were different. In this instance $10 \mathrm{ml}$ of diluted phosphoric acid $(1+9)$ was added directly instead of dropping in the more diluted acid $(1+99)$.

Separation of Bromide. The apparatus was assembled as in 5.1, except that tube $\mathrm{H}$ and flask I

\footnotetext{
3 The side necks of flask A were gently heated with a torch to drive over the iodine that condensed there.

4 On turning off the heat, it was necessary to open the stopcock on B and to disconnect the vacuum to prevent the solution in $\mathrm{G}$ from sucking back.
}

were omitted and that 0.5 -percent hydrazine sulfate solution was used in flask G. A piece of platinum gauze and $60 \mathrm{ml}$ of diluted nitric acid $(1+1)$ were added to the solution in flask $A$. The purpose of the platinum gauze was to catalyze the decomposition of the hydrogen peroxide present. The solution was refluxed until the peroxide was decomposed, and then for 30 minutes longer. The solution was slowly distilled until no visual evidence of bromine remained or until $25 \mathrm{ml}$ had distilled if no bromine was noted. Tube $\mathrm{F}$ was rinsed and the washings caught directly in flask G. The flask and contents were reserved for the determination of bromide.

Separation of Chloride. If more than 0.1 percent ( $1 \mathrm{mg}$ ) of chloride was present, the chloride was determined without further treatment. If less than 0.1 percent $(1 \mathrm{mg})$ of chloride was present, the following method was used:

The apparatus was assembled as in the separation of bromide. Fifteen milliliters of potassium permanganate reagent solution was added to flask A through the delivery funnel. The solution was heated to boiling, refluxed for 30 minutes, $25 \mathrm{ml}$ slowly distilled into flask $\mathrm{G}$, and this solution saved for the determination of chloride. This isolation of the small amount of chloride is advantageous because the chloride is thus concentrated in a small volume of solution that is free from substances such as nitric acid that might have a solvent effect on the silver chloride.

\subsection{Bromide as the Major Constituent, Iodide and Chloride as Minor Constituents}

Separation of Iodide. The apparatus was assembled as in the separations of bromide and chloride in 5.2. Using this modified apparatus, the iodide was separated as in 5.2 except that at the end of this separation a second apparatus similar to the first was set up in which flask $\mathrm{G}$ of the first apparatus became flask $A^{\prime}$ of the second one. One-half gram of dipotassium hydrogen phosphate, $2 \mathrm{ml}$ of 30-percent hydrogen peroxide, and $10 \mathrm{ml}$ of diluted phosphoric acid $(1+9)$ were added to this flask. The resulting solution was heated to boiling, refluxed for 30 minutes, and $25 \mathrm{ml}$ was slowly distilled into flask $\mathrm{G}^{\prime}$. The solution in this flask was saved for the determination of iodide. The solution in flask $\mathrm{A}^{\prime}$ was poured into flask A.

This is, in effect, a second treatment and separation of the iodide, necessary because of the small amount of bromide that comes over in the first separation. The role of the dipotassium hydrogen phosphate is not clear, but halogens appear to distill from solutions that contain it faster than from those that do not.

Separation of Bromide. The method outlined for the separation of bromide in 5.1 was followed, except that a piece of platinum gauze was added to hasten the decomposition of the peroxide, and $30 \mathrm{ml}$ of concentrated nitric acid was used instead of $60 \mathrm{ml}$ of diluted nitric acid $(1+1)$.

Separation of Chloride. The procedure outlined for the separation of chloride in 5.2 was followed. 


\subsection{Chloride as Major Constituent, Iodide and Bromide as Minor Constituents}

Separation of Iodide. The iodide was separated as in 5.3, except that a second treatment and separation were not necessary.

Separation of Bromide. The method outlined for the separation of bromide in 5.2 was followed, except that at the end of this separation a second apparatus similar to the first was set up in which flask $\mathrm{G}$ of the first apparatus became flask $\mathrm{A}^{\prime}$ of the second apparatus. One-half gram of dipotassium hydrogen phosphate, $50 \mathrm{ml}$ of water, and $15 \mathrm{ml}$ of nitric acid were added to the solution in flask $\mathrm{A}^{\prime}$ and the same procedure followed as in the first separation. This second treatment served to separate the bromide from the small amount of chloride that distilled in the first separation. After the second separation the solution in flask $A^{\prime}$ was poured into flask $A$.

Separation of Chloride. The procedure outlined for the separation of chloride in 5.1 was followed.

\subsection{Halides Present as Minor Constituents}

Separation of Iodide. The procedure outlined for the separation of iodide in 5.3 was followed, except that a second treatment and separation were not necessary and that $0.5 \mathrm{~g}$ of dipotassium hydrogen phosphate was added to flask A before the separation.

Separation of Bromide. The procedure outlined for the separation of bromide in 5.2 was followed.

Separation of Chloride. The procedure outlined for the separation of chloride in 5.2 was followed.

\section{Determination of the Separated Halides}

In the above procedures the separated halides were determined by two different methods, depending on the concentration of the halide. When the halide was in excess of $1 \mathrm{mg}$, a potentiometric titration method was used, and when present in less than this amount, a turbidimetric method was used.

\subsection{Potentiometric Method}

The potentiometric method was based on a variation of the method of Lange and Schwartz [12]. The apparatus consisted of the following items: Vacuumtube voltmeter with full scale of $100 \mathrm{mv}$; silver electrode; calomel electrode; salt bridge, consisting of a glass tube fitted with fine porous frits at the ends and filled with a solution containing 1 part of glycerine and 1 part of a saturated aqueous solution of ammonium nitrate; and magnetic stirring apparatus.

The 3-neck flask containing the separated halide was placed on the stage of the magnetic stirrer, and a Teflon-coated stirring bar was placed in the flask. The salt bridge was inserted into a side neck of the 3-neck flask so that it reached below the surface of the solution. The silver electrode was inserted through the other side neck in a similar manner. The other end of the salt bridge was immersed in the calomel electrode, and the silver and calomel electrodes were connected to the voltmeter. When chloride was being determined, it was necessary to cool the flask in an ice bath during the titration. During all determinations it was necessary to shield the flask from light. This was accomplished by enclosing the assembly in black paper.

Standardized silver nitrate was added from a weight buret until the end point was approached, usually to within 1 percent of the theoretical amount required. The titration was completed by using $0.01 \mathrm{~N}$ silver nitrate. The change in electromotive force produced by the addition of known amounts of the silver nitrate solution was recorded, and the end point was determined by the method of plotting $\Delta E / \Delta v$ with respect to the volume, $v$, of solution added. From the weight of the first silver nitrate solution and the volume of the second, the amount of halide was calculated.

\subsection{Turbidimetric Method}

When the halide content was small (less than 1 mg), a turbidimetric method was used after suitable dilution. The method was as follows:

The solution in flask $\mathrm{G}$ was diluted so as to contain from 0.01 to $0.05 \mathrm{mg}$ of halide in $50 \mathrm{ml}$ of solution. Controls containing varying amounts of halides (e. g., $0.01,0.02,0.03 \mathrm{mg}$ of halide) and the same amount of hydrazine sulfate as in $50 \mathrm{ml}$ of the diluted sample solution were prepared. One milliliter of nitric acid and $1 \mathrm{ml}$ of $0.1 N$ silver nitrate were added to the $50-\mathrm{ml}$ portion of the sample solution and to the controls. The turbidities produced were compared visually in Nessler tubes.

\section{Results}

Table 1 shows the results obtained for the separa tion and determination of known amounts of halides when at least $1 \mathrm{mg}$ of each halide was present. The separations were all performed according to the procedure outlined in section 5.1. The determinations were all by the potentiometric method.

Table 2 shows the results obtained for the separation and determination of known amounts of halides when one of the halides was present as a major constituent, with the other two halides as minor constituents. The separations were all performed according to the procedures outlined in sections 5.2., 5.3., and 5.4. The major constituent was not determined because the results shown in table 1 prove that large amounts of halides can be recovered. The minor constituents (halides) were determined by the turbidimetric method.

Table 3 shows the results obtained for the isolation and determination of small known amounts of the halides in the order of $1 \mathrm{mg}$ or less of each. The separations were all done as in the procedure given in section 5.5. The determinations were all by the turbidimetric method.

The results given in tables 2 and 3 were corrected for any halide present in the reagents.

As shown in table 1, there was a standard deviation of $0.0002 \mathrm{~g}$ for the iodide determinations, $0.0002 \mathrm{~g}$ for the bromide determinations, and $0.0003 \mathrm{~g}$ for the chloride determinations. Because all determinations reported in tables 2 and 3 were made by a 
TABLE 1. Results obtained when halide was a major constituent

\begin{tabular}{|c|c|c|c|c|c|c|c|c|c|c|}
\hline \multirow{2}{*}{ Approximate composition } & \multirow{2}{*}{$\begin{array}{l}\text { Solu- } \\
\text { tion } \\
\text { No. }\end{array}$} & \multicolumn{3}{|c|}{ Iodide } & \multicolumn{3}{|c|}{ Bromide } & \multicolumn{3}{|c|}{ Chloride } \\
\hline & & Present & Found & Error & Present & Found & Error & Present & Found & Error \\
\hline $33 \% \mathrm{KI}, 33 \% \mathrm{NaBr}, 33 \% \mathrm{KCl}$ & $\left\{\begin{array}{l}1 \\
2 \\
3 \\
4\end{array}\right.$ & $\begin{array}{c}g \\
0.2377 \\
.2844 \\
.2714 \\
.2533\end{array}$ & $\begin{array}{c}g \\
0.2378 \\
.2846 \\
.2719 \\
.2532\end{array}$ & $\begin{array}{c}g \\
0.0001 \\
.0002 \\
.0005 \\
.0001\end{array}$ & $\begin{array}{c}g \\
0.2475 \\
.2715 \\
.2764 \\
.2676\end{array}$ & $\begin{array}{c}g \\
0.2472 \\
.2716 \\
.2765 \\
.2680\end{array}$ & $\begin{array}{c}g \\
0.0003 \\
.0001 \\
.0001 \\
.0004\end{array}$ & $\begin{array}{c}g \\
0.1143 \\
.1871 \\
.1761 \\
.1517\end{array}$ & $\begin{array}{c}g \\
0.1143 \\
.1868 \\
.1761 \\
.1514\end{array}$ & $\begin{array}{c}g \\
0.0000 \\
.0003 \\
.0000 \\
.0003\end{array}$ \\
\hline $15 \% \mathrm{KI}, 15 \% \mathrm{NaBr}, 70 \% \mathrm{KCl}$ & $\left\{\begin{array}{l}5 \\
6\end{array}\right.$ & $\begin{array}{l}.1437 \\
.0763\end{array}$ & $\begin{array}{l}.1438 \\
.0765\end{array}$ & $\begin{array}{l}.0001 \\
.0002\end{array}$ & $\begin{array}{l}.1277 \\
.0804\end{array}$ & $\begin{array}{l}.1276 \\
.0804\end{array}$ & $\begin{array}{l}.0001 \\
.0000\end{array}$ & $\begin{array}{l}.2923 \\
.3958\end{array}$ & $\begin{array}{l}.2917 \\
.3953\end{array}$ & $\begin{array}{l}.0006 \\
.0005\end{array}$ \\
\hline $15 \% \mathrm{KI}, 60 \% \mathrm{NaBr}, 25 \% \mathrm{KCl}$ & $\left\{\begin{array}{l}7 \\
8\end{array}\right.$ & $\begin{array}{l}.1191 \\
.1100\end{array}$ & $\begin{array}{l}.1190 \\
.1099\end{array}$ & $\begin{array}{l}.0001 \\
.0001\end{array}$ & $\begin{array}{l}.4599 \\
.4656\end{array}$ & $\begin{array}{l}.4598 \\
.4655\end{array}$ & $\begin{array}{l}.0000 \\
.0001\end{array}$ & $\begin{array}{l}.1012 \\
.1328\end{array}$ & $\begin{array}{l}.1012 \\
.1322\end{array}$ & $\begin{array}{l}.0000 \\
.0006\end{array}$ \\
\hline $60 \% \mathrm{KI}, 15 \% \mathrm{NaBr}, 25 \% \mathrm{KCl}$ & $\left\{\begin{array}{r}9 \\
10\end{array}\right.$ & $\begin{array}{l}.4690 \\
.4596\end{array}$ & $\begin{array}{l}.4689 \\
.4595\end{array}$ & $\begin{array}{l}.0001 \\
.0001\end{array}$ & $\begin{array}{l}.0829 \\
.0870\end{array}$ & $\begin{array}{l}.0828 \\
.0870\end{array}$ & $\begin{array}{l}.0001 \\
.0000\end{array}$ & $\begin{array}{l}.1264 \\
.1029\end{array}$ & $\begin{array}{l}.1266 \\
.1030\end{array}$ & $\begin{array}{l}.0002 \\
.0001\end{array}$ \\
\hline $2 \% \mathrm{KI}, 2 \% \mathrm{NaBr}, 96 \% \mathrm{KCl}_{-}$ & $\left\{\begin{array}{l}11 \\
12\end{array}\right.$ & $\begin{array}{l}.0078 \\
.0096\end{array}$ & $\begin{array}{l}.0077 \\
.0096\end{array}$ & $\begin{array}{l}.0001 \\
.0000\end{array}$ & $\begin{array}{l}.0098 \\
.0113\end{array}$ & $\begin{array}{l}.0098 \\
.0115\end{array}$ & $\begin{array}{l}.0000 \\
.0002\end{array}$ & $\begin{array}{l}4849 \\
.4784\end{array}$ & $\begin{array}{l}.4849 \\
.4781\end{array}$ & $\begin{array}{l}.0000 \\
.0003\end{array}$ \\
\hline $96 \% \mathrm{KI}, 2 \% \mathrm{NaBr}, 2 \% \mathrm{KCl}$ & $\left\{\begin{array}{l}13 \\
14\end{array}\right.$ & $\begin{array}{l}.7658 \\
.7531\end{array}$ & $\begin{array}{l}.7658 \\
.7530\end{array}$ & $\begin{array}{l}.0000 \\
.0001\end{array}$ & $\begin{array}{l}.0098 \\
.0088\end{array}$ & $\begin{array}{l}.0097 \\
.0088\end{array}$ & $\begin{array}{l}.0001 \\
.0000\end{array}$ & $\begin{array}{l}.0078 \\
.0061\end{array}$ & $\begin{array}{l}.0077 \\
.0061\end{array}$ & $\begin{array}{l}.0001 \\
.0000\end{array}$ \\
\hline $2 \% \mathrm{KI}, 96 \% \mathrm{NaBr}, 2 \% \mathrm{KCl} \ldots$ & $\left\{\begin{array}{l}15 \\
16\end{array}\right.$ & $\begin{array}{l}.0070 \\
.0081\end{array}$ & $\begin{array}{l}.0070 \\
.0081\end{array}$ & $\begin{array}{l}.0000 \\
.0000\end{array}$ & $\begin{array}{l}.7743 \\
.7716\end{array}$ & $\begin{array}{l}.7742 \\
.7714\end{array}$ & $\begin{array}{l}.0001 \\
.0002\end{array}$ & $\begin{array}{l}.0062 \\
.0052\end{array}$ & $\begin{array}{l}.0063 \\
.0053\end{array}$ & $\begin{array}{l}.0001 \\
.0001\end{array}$ \\
\hline Standard deviation. & & & & 0.0002 & & & 0.0002 & & & 0.0003 \\
\hline
\end{tabular}

TABLE 2. Results obtained when two of the halides were minor constituents, and the third a major constituent

\begin{tabular}{|c|c|c|c|c|c|c|c|}
\hline \multirow{2}{*}{ Approximate composition } & \multirow{2}{*}{$\begin{array}{c}\text { Solu- } \\
\text { tion } \\
\text { No. }\end{array}$} & \multicolumn{2}{|c|}{ Iodide } & \multicolumn{2}{|c|}{ Bromide } & \multicolumn{2}{|c|}{ Chloride } \\
\hline & & Added & Found & Added & Found & Added & Found \\
\hline $0.1 \% \mathrm{I}, 0.1 \% \mathrm{Br}$, rest $\mathrm{KCl}_{-}$ & $\left\{\begin{array}{l}1 \\
2\end{array}\right.$ & $\begin{array}{l}m g \\
1.0 \\
1.0\end{array}$ & $\begin{array}{l}m g \\
1.0 \\
1.0\end{array}$ & $\begin{array}{l}m g \\
1.0 \\
1.0\end{array}$ & $\begin{array}{l}m g \\
1 . \theta \\
1.0\end{array}$ & $m g$ & $\begin{array}{c}m g \\
-\end{array}$ \\
\hline $0.1 \% \mathrm{I}, 0.1 \% \mathrm{Cl}$ rest $\mathrm{NaBr} \ldots$ & $\left\{\begin{array}{l}3 \\
4\end{array}\right.$ & $\begin{array}{l}1.0 \\
1.0\end{array}$ & $\begin{array}{l}1.0 \\
1.0\end{array}$ & - & - & $\begin{array}{l}1.0 \\
1.0\end{array}$ & $\begin{array}{l}1.0 \\
1.0\end{array}$ \\
\hline $0.1 \% \mathrm{Br}, 0.1 \% \mathrm{Cl}$, rest $\mathrm{KI}_{--}$ & $\begin{array}{l}5 \\
6\end{array}$ & - & - & $\begin{array}{l}1.0 \\
1.0\end{array}$ & $\begin{array}{l}1.0 \\
1.0\end{array}$ & $\begin{array}{l}1.0 \\
1.0\end{array}$ & $\begin{array}{l}1.0 \\
1.0\end{array}$ \\
\hline $0.01 \% \mathrm{I}, 0.01 \% \mathrm{Br}$, rest $\mathrm{KCl}_{-}$ & $\left\{\begin{array}{l}7 \\
8\end{array}\right.$ & $\begin{array}{r}0.1 \\
.1\end{array}$ & $\begin{array}{r}0.1 \\
.1\end{array}$ & $\begin{array}{r}0.1 \\
.1\end{array}$ & $\begin{array}{r}0.1 \\
.1\end{array}$ & - & - \\
\hline $0.01 \% \mathrm{I}, 0.01 \% \mathrm{Cl}$, rest $\mathrm{NaBr}$ & $\left\{\begin{array}{r}9 \\
10\end{array}\right.$ & $\begin{array}{l}.1 \\
.1\end{array}$ & $\begin{array}{l}.1 \\
.1\end{array}$ & -..... & -... & $\begin{array}{r}0.1 \\
.1\end{array}$ & $\begin{array}{r}0.1 \\
.1\end{array}$ \\
\hline $0.01 \% \mathrm{Br}, 0.01 \% \mathrm{Cl}$, rest $\mathrm{KI}$ - & $\left\{\begin{array}{l}11 \\
12\end{array}\right.$ & - & - & $\begin{array}{l}.1 \\
.1\end{array}$ & $\begin{array}{l}.1 \\
.1\end{array}$ & $\begin{array}{l}.1 \\
.1\end{array}$ & $\begin{array}{l}.1 \\
.1\end{array}$ \\
\hline $0.001 \% \mathrm{I}, 0.001 \% \mathrm{Br}$, rest $\mathrm{KCl}_{-}$ & $\left\{\begin{array}{l}13 \\
14\end{array}\right.$ & $\begin{array}{l}.01 \\
.01\end{array}$ & $\begin{array}{l}.01 \\
.01\end{array}$ & $\begin{array}{l}.01 \\
.01\end{array}$ & $\begin{array}{l}.01 \\
.01\end{array}$ & - & - \\
\hline $0.001 \% \mathrm{Br}, 0.001 \% \mathrm{Cl}$, rest $\mathrm{KI}$ & $\left\{\begin{array}{l}15 \\
16\end{array}\right.$ & - & - & $\begin{array}{l}.01 \\
.01\end{array}$ & $\begin{array}{l}.01 \\
.01\end{array}$ & $\begin{array}{l}.01 \\
.01\end{array}$ & $\begin{array}{l}.01 \\
.01\end{array}$ \\
\hline
\end{tabular}

visual turbidimetric method, standard deviations were not calculated, as they would be meaningless. For all practical purposes, the recovery of added halides in these determinations may be regarded as 100 percent.

\section{References}

[1] F. A. Gooch and F. W. Mar, Am. J. Sci. 39, 293 (1890).

[2] H. Wales, J. Assoc. Offic. Agr. Chemists 12, 302 (1929).

[3] L. W. Winkler, Z. angew. Chem. 28, 477 (1915).

[4] N. E. Freeman, J. Assoc. Offic. Agr. Chemists 14, 338 (1931).

[5] N. E. Freeman, J. Assoc. Offic. Agr. Chemists 25, 833 (1942)

[6] W. M. Latimer, Oxidation potentials, 2d ed. (PrenticeHall, Inc., New York, N. Y., 1952).

[7] W. C. Bray and H. A. Liebhafsky, J. Am. Chem. Soc. 53, 38 (1931).

[8] R. S. Livingston and W. C. Bray, J. Am. Chem. Soc. 45, 2048 (1923).

[9] R. S. Livingston and W. C. Bray, J. Am. Chem. Soc. 47, 2069 (1925).
TABLE 3. Results obtained when halide was a minor constituent

\begin{tabular}{|c|c|c|c|c|c|c|}
\hline \multirow{2}{*}{$\begin{array}{l}\text { Solution } \\
\text { No. }\end{array}$} & \multicolumn{2}{|c|}{ Iodide } & \multicolumn{2}{|c|}{ Bromide } & \multicolumn{2}{|c|}{ Chloride } \\
\hline & Added & $\begin{array}{l}\text { Recov- } \\
\text { ered }\end{array}$ & Added & $\begin{array}{c}\text { Recov- } \\
\text { ered }\end{array}$ & Added & $\begin{array}{c}\text { Recov- } \\
\text { ered }\end{array}$ \\
\hline $\begin{array}{l}1 \\
2 \\
3\end{array}$ & $\begin{array}{c}m g \\
1.0 \\
1.0 \\
.10\end{array}$ & $\begin{array}{c}\mathrm{mg} \\
\text { 1. } 0 \\
\text { 1. } 0 \\
.10\end{array}$ & $\begin{array}{c}m g \\
1.0 \\
1.0 \\
.10\end{array}$ & $\begin{array}{c}m g \\
1.0 \\
1.0 \\
.10\end{array}$ & $\begin{array}{c}m g \\
1.0 \\
1.0 \\
.10\end{array}$ & $\begin{array}{c}m g \\
1.0 \\
.9 \\
.10\end{array}$ \\
\hline $\begin{array}{l}4 \\
5 \\
6\end{array}$ & $\begin{array}{l}.10 \\
.01 \\
.01\end{array}$ & $\begin{array}{l}.10 \\
.01 \\
.01\end{array}$ & $\begin{array}{l}.10 \\
.01 \\
.01\end{array}$ & $\begin{array}{l}.10 \\
.01 \\
.01\end{array}$ & $\begin{array}{l}.10 \\
.01 \\
.01\end{array}$ & $\begin{array}{l}.10 \\
.01 \\
.01\end{array}$ \\
\hline
\end{tabular}

[10] L. F. Kebler, J. Anal. App. Chem. 6, 569 (1892).

[11] E. M. Chamot and C. W. Mason, Mikrochem. 5, 85 (1927).

[12] I. M. Kolthoff and N. H. Furman, Potentiometric titrations, 2d ed., p. 148 (John Wiley \& Sons, Inc., New York, N. Y., 1940).

Washington, April 13, 1954. 